\title{
Análise da Influência da Adição de Sílica Ativa como Substituição Parcial do Cimento em Argamassas Contra Ação de $\mathrm{CO}_{2}$ e Íons Cloreto
}

\author{
Analysis of the Influence of the Addition of Active Silica as Partial Substitution of the \\ Cement in Mortars against $\mathrm{CO}_{2}$ and Chloride Ions Action
}

\author{
Ariane Cardoso ${ }^{1}$ (iD) orcid.org/0000-0001-9199-4714 \\ Thayse Delmiro ${ }^{1}$ (iD) orcid.org/0000-0002-4514-4214 \\ Aldileide Mendes ${ }^{2}$ (i) orcid.org/0000-0002-1183-1200 \\ Eliana Monteiro 1,2 (id) orcid.org/0000-0003-0842-779X \\ Emilia KohIman Rabbani ${ }^{1}$ (id) orcid.org/0000-0002-4016-5198 \\ ${ }^{1}$ Departamento de Engenharia Civil, Universidade de Pernambuco, Recife, Brasil. \\ 2 Departamento de Engenharia Civil, Universidade Católica de Pernambuco, Recife, Brasil. \\ E-mail do autor principal: Ariane Cardoso ariane_cardoso@hotmail.com
}

\section{Resumo}

\begin{abstract}
A sílica ativa promete promover maior durabilidade ao concreto, pois proporciona uma barreira física à penetração dos agentes agressivos. No entanto, alguns pesquisadores afirmam que aumenta a profundidade de carbonatação devido à redução da reserva alcalina. Objetivando entender esse comportamento, buscou-se analisar a influência da sílica ativa em argamassas, frente à ação de $\mathrm{CO}_{2}$ e íons cloreto. Utilizaram-se traços com $10 \%$ e $15 \%$ da adição em substituição do cimento Portland, e relação água/aglomerante de 0,5 e 0,7, nos quais se verificaram a profundidade de carbonatação através do emprego do indicador de fenolftaleína, e a penetração de cloretos através do método colorimétrico de aspersão de nitrato de prata. A utilização da sílica ativa reduziu a profundidade de penetração de cloretos em até $29,88 \%$. Quanto a proteção frente à ação de $\mathrm{CO}_{2}$, apenas a substituição de $10 \%$ se mostrou benéfica para as amostras com relação a/agl 0,5 , reduzindo a profundidade carbonatada em $13,08 \%$ e nos demais traços apresentou um aumento na profundidade de carbonatação de no máximo 5,48\%. Desta forma não se descarta sua utilização em concretos com baixo fator a/agl para melhorias nas suas características, além de proporcionar uma redução na utilização de cimento e consequentemente uma menor poluição atmosférica.
\end{abstract}

Palavras-Chave: Manifestações Patológicas; Concreto; Corrosão; Sílica ativa;

\section{Abstract}

The active silica promises to promote greater durability to the concrete, as it provides a physical barrier to the penetration of aggressive agents. However, some researchers say it increases the carbonation depth due to the alkaline reserve reduction. Aiming to understand this behavior, we sought to analyze the influence of active silica on mortars, as opposed to the action of $\mathrm{CO}_{2}$ and chloride ions. Traces with $10 \%$ and $15 \%$ of the addition were used instead of Portland cement and 167

http: / / dx.doi.org/10.25286/repa.v2i3.714 
water/agglomerate ratio of 0.5 and 0.7 at which the carbonation depth was verified through the use of the phenolphthalein indicator, and penetration of chlorides through the colorimetric silver nitrate spray method. The use of active silica reduced the penetration depth of chlorides by up to $29.88 \%$. As for the protection against $\mathrm{CO}_{2}$ action, only the substitution of $10 \%$ was beneficial for the samples with respect to a/agl 0.5 , reducing the carbonated depth in $13.08 \%$ and in the other traces presented an increase in the depth of carbonation of a maximum of $5.48 \%$. In this way it is not ruled out its use in concretes with low a/agl factor for improvements in its characteristics, besides providing a reduction in the use of cement and consequently a lower atmospheric pollution.

Key-words: Pathological Manifestations; Concrete; Corrosion; Active Silica;

\section{Introdução}

O concreto é parte integrante de praticamente todas as construções, de edificações residenciais a grandes obras de infraestrutura como pontes e estradas. De acordo com Mehta e Monteiro, embora não se apresente tão resistente quanto o aço, o concreto possui resistência a agressões físicas e químicas do ambiente, mostra-se de fácil execução e adaptabilidade a qualquer forma de construção, possui menor custo e é mais facilmente produzido no canteiro de obra [1]. Devido sua versatilidade, tornou-se o segundo material mais consumido no mundo, perdendo apenas para água [2].

Entretanto, o concreto poderá apresentar inúmeras manifestações patológicas que são causadas por diversos fatores. Barbosa et al. consideram que o fenômeno da corrosão das armaduras é mais frequente do que qualquer outro fenômeno de deterioração das estruturas de concreto armado, comprometendo-as tanto esteticamente, quanto do ponto de vista de segurança [3]. Estima-se que a corrosão de armaduras em concreto destrua $25 \%$ da produção mundial de aço por ano além de ser responsável por perdas humanas, devido à queda de viadutos, pontes e edifícios [4]. No Brasil, este cenário é preocupante, pois muitas das grandes cidades são litorâneas, estando submetidas a agentes extremamente agressivos como os cloretos além de que a agressividade do meio ambiente vem aumentando significativamente com 0 desenvolvimento descontrolado mundial, contribuindo desta forma para a redução da vida útil das estruturas.

A corrosão pode ser desencadeada por meio de dois agentes principais, sendo eles a ação de íons cloreto, o qual afeta a película passivadora, e a carbonatação, que reduz $0 \mathrm{pH}$ de precipitação do concreto, reduzindo a estabilidade da película 168 passivadora. Ela ainda pode manifestar-se de diferentes formas, sendo a corrosão generalizada e a puntiforme os casos mais comuns. A primeira, em geral não provoca danos muito graves por afetar toda a extensão da armadura. A segunda, por se concentrar em pontos específicos, acaba sendo mais danosa causando a perda do desempenho estrutural, podendo acarretar uma ruptura frágil em seção definida e sem aviso [5].

Os efeitos degenerativos provenientes da corrosão levam a um comprometimento da segurança estrutural ao longo do tempo, e manifestam-se na forma de manchas superficiais, seguidas por fissuras, destacamento do concreto de cobrimento, redução da seção das armaduras com frequente seccionamento de estribos e redução e eventual perda de aderência das armaduras principais [6].

$\mathrm{Na}$ tentativa de melhorar as propriedades do concreto e minimizar os efeitos dos agentes agressivos, a sílica ativa vem sendo consumida em grande escala.

Barata verificou que a adição de sílica ativa proporciona as misturas de concreto maior coesão, facilidade de acabamento e redução da exsudação [7]. Contudo, Helene chama atenção que "embora as adições melhorem consideravelmente as propriedades do concreto reduzindo a permeabilidade, a porosidade e aumentando a resistência à compressão, ao mesmo tempo aumentam a velocidade de carbonatação", o que o autor explica devido ao teor de álcalis disponível para as reações de carbonatação [8].

A Sílica Ativa é um subproduto de origem metalúrgica, obtido do processo de fabricação do silício metálico ou ferro silício a partir de quartzo de elevada pureza e carvão ou coque (fonte de carbono), cavacos de madeira e, eventualmente, o minério de ferro no caso da produção de ferro silício, o que the 
confere maior estabilidade quanto a sua composição física e química [9][7].

Monteiro e Pereira ao estudarem a capacidade de proteção de alguns tipos de cimentos em relação à corrosão de armaduras sob a ação conjunta de $\mathrm{CO}_{2}$ e íons cloretos, constataram que corpos de prova não carbonatos, apresentaram intensidades de corrosão muito menores em relação aos corpos de prova semelhantes carbonatados, quando submetidos às mesmas condições de ciclos em uma solução de cloreto com a mesma concentração [10].

Por outro lado, além da preocupação em melhorar as características do concreto, existe uma constante preocupação com a poluição causada pela indústria da construção. Estudos internacionais apontam que aproximadamente $5 \%$ das emissões de $\mathrm{CO}_{2}$ de origem antrópica no mundo provêm da produção do cimento. No Brasil, esse valor corresponde a 1,4\% de acordo com o Inventário Nacional de Gases de Efeito Estufa, divulgado em 2010 segundo Kihara e Visedo [11]. A utilização de adições tem representado uma das mais eficazes medidas de controle e redução das emissões de $\mathrm{CO}_{2}$ da indústria. O país apresenta a menor relação clínquer/cimento e, consequentemente, o maior percentual de adições utilizadas, colocando mais uma vez esta nação como referência internacional na busca por cimentos melhores e com menor emissão [11].

Nota-se, diante de todo o exposto, a complexa questão da utilização de sílica ativa em concretos que por um lado tem-se um comportamento favorável frente à ação de cloretos e, por outro lado, um aspecto desfavorável quanto a maior velocidade e profundidade da frente de carbonatação. Por esses motivos, se faz necessário cada vez mais estudos que comprovem a influência dessa substituição no concreto.

\section{Objetivo}

Analisar a influência da adição da sílica ativa em substituição parcial do cimento na capacidade de proteção da argamassa sob a ação de $\mathrm{CO}_{2}$ e íons cloretos, utilizando diferentes relações água/aglomerante.

\section{Método de pesquisa}

O programa experimental buscou avaliar a presença de cloretos livres através do método colorimétrico de aspersão da solução de nitrato de prata com base na norma italiana UNI 7928 (1978) [12], e a verificação da profundidade de carbonatação através de aspersão da solução de fenolftaleína baseado na norma RILEM CPC-18 (1998) [13], em argamassas confeccionadas com o cimento Portland CPII Z - 32, com relações água/aglomerante 0,5 e 0,7 e substituição parcial do cimento por $10 \%$ e $15 \%$ de sílica ativa. A Figura 1 apresenta o fluxograma com quantidade de corpos de provas confeccionados para cada ensaio.

Adotou-se para o estudo a utilização de argamassas, devido às pequenas dimensões dos corpos de prova e com a intenção de simular o cobrimento do concreto, moldados de acordo com as recomendações da NBR 7215 (ABNT, 1996) [14], utilizando o traço 1:3. A escolha da relação água/aglomerante se deu em função dos valores comumente praticados na região.

Para a verificação da profundidade de carbonatação, objetivando simular uma situação real de exposição, as amostras permaneceram previamente expostas por 30 dias em ambiente de laboratório e 30 dias na garagem de uma edificação residencial, com provável concentração de $\mathrm{CO}_{2}$ em torno de $1 \%$ e umidade relativa média do ar de $86 \%$, por um período de 30 dias. O ensaio consiste em mensurar a profundidade de carbonatação através da aspersão de uma solução com indicador químico na peça recém-fraturada para que a face a ser analisada não venha sofrer a interferência do $\mathrm{CO}_{2}$ do ar. Para a execução do ensaio, cada amostra foi rompida à tração por compressão diametral e borrifada em sua face interna a solução de fenolftaleína. A profundidade foi verificada visualmente pela diferença de coloração do chamado ponto de viragem da fenolftaleína. O valor da frente de carbonatação foi baseado em seis leituras das maiores profundidades de uma face para no fim compilar uma média, realizadas através de um paquímetro, sendo expresso em milímetros. Os valores encontrados foram submetidos a uma análise estatística de variância, onde aqueles que diferiram muito da média, foram descartados, mantendo assim um coeficiente de variação menor do que 15\%, garantindo uma baixa dispersão dos dados e uma maior confiabilidade nos resultados. Os dados estão representados em um gráfico, por meio de seus respectivos valores médios. 


\begin{tabular}{|c|c|c|c|c|c|c|c|}
\hline \multicolumn{8}{|c|}{ DETECÇÃO DO ENSAIO } \\
\hline \multicolumn{4}{|c|}{+} & \multicolumn{4}{|c|}{.+} \\
\hline \multicolumn{4}{|c|}{ CLORETOS } & \multicolumn{4}{|c|}{ CARBONATAÇÃo } \\
\hline \multicolumn{4}{|c|}{ i } & \multicolumn{4}{|c|}{4} \\
\hline \multicolumn{4}{|c|}{$\begin{array}{c}\text { MÉTODO COLORIMÉTRICO DE ASPERSÃO } \\
\text { DA SOLUÇÃO DE NITRATO DE PRATA }\end{array}$} & \multicolumn{4}{|c|}{ INDICADOR DE FENOLFTALEINA } \\
\hline \multicolumn{4}{|c|}{1} & \multicolumn{4}{|c|}{6} \\
\hline \multicolumn{4}{|c|}{4 ciclos de indução } & \multicolumn{4}{|c|}{$\begin{array}{l}30 \text { dias exposto em ambiente de laboratório } \\
30 \text { dias expostos em edifício garagem }\end{array}$} \\
\hline \multicolumn{4}{|c|}{1} & \multicolumn{4}{|c|}{+} \\
\hline \multicolumn{4}{|c|}{ NÚMERO DE AMOSTRAS } & \multicolumn{4}{|c|}{ NÚMERO DE AMOSTRAS } \\
\hline Adição & $\%$ & a/agl & quant. & Adição & $\%$ & a/agl & quant. \\
\hline \multirow{4}{*}{ Sílica Ativa } & \multirow{2}{*}{$10 \%$} & 0,5 & 7 & \multirow{4}{*}{ Sílica Ativa } & \multirow{2}{*}{$10 \%$} & 0,5 & 7 \\
\hline & & 0,7 & 7 & & & 0,7 & 7 \\
\hline & \multirow{2}{*}{$15 \%$} & 0,5 & 7 & & \multirow{2}{*}{$15 \%$} & 0,5 & 7 \\
\hline & & 0,7 & 7 & & & 0,7 & 7 \\
\hline \multirow{2}{*}{ Referência } & \multirow{2}{*}{$0 \%$} & 0,5 & 7 & \multirow{2}{*}{ Referência } & \multirow{2}{*}{$0 \%$} & 0,5 & 7 \\
\hline & & 0,7 & 7 & & & 0,7 & 7 \\
\hline \multicolumn{4}{|c|}{1} & \multicolumn{4}{|c|}{$b$} \\
\hline \multicolumn{4}{|c|}{ Total $=42$ CP's } & \multicolumn{4}{|c|}{ Total $=42$ CP's } \\
\hline
\end{tabular}

Figura 1: Fluxograma com as famílias confeccionadas para cada ensaio. Fonte: Autores (2016).

Para verificação da presença de cloretos livres o ensaio foi baseado na norma italiana UNI 7928 (1978) [12], que estipula uma solução de nitrato de prata com concentração de $0,1 \mathrm{~mol} / \mathrm{l}$, ou seja, $17 \mathrm{~g}$ de $\mathrm{AgNO}_{3}$ para 1 litro de água destilada. Adotou-se para esta pesquisa o método utilizado por Monteiro, onde os corpos de prova foram submetidos à ciclos de secagem com duração de 5 dias em estufa à $50^{\circ} \mathrm{C}$ e à ciclos de imersão parcial em uma solução de $5 \% \mathrm{NaCl}$, com duração de 2 dias. Completados os 4 ciclos, seguidos de mais uma etapa de secagem, as amostras foram rompidas à tração por compressão diametral e em seguida efetuou-se a aspersão de uma solução de nitrato de prata com concentração de $0,1 \mathrm{M}$ na superfície interna [15]. As amostras permaneceram em ambiente iluminado no período de 15 minutos, para que a reação fotoquímica entre a solução e a superfície da argamassa ocorresse. Posteriormente realizaram-se as leituras por meio de um paquímetro de acordo com as recomendações da NT BUILD 492 (2000) [16] através da realização de sete medidas para no fim compilar uma média.

A Figura 2 apresenta as amostras após os ensaios de presença de cloretos e profundidade de carbonatação.

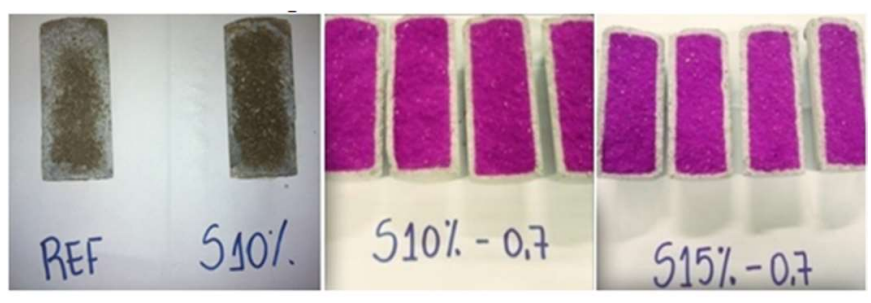

Cloretos

Carbonatação

Figura 2: Amostras ensaiadas.

Fonte: Autores (2016). 


\section{Resultados}

\subsection{Ação do $\mathrm{CO}_{2}$}

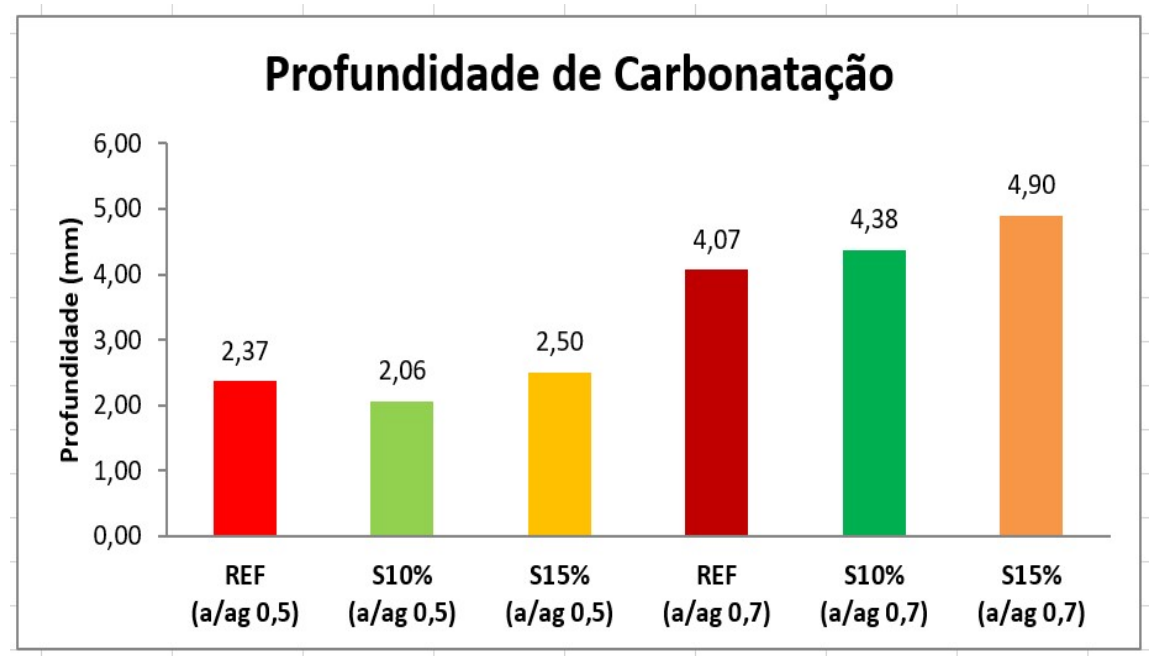

Figura 3: Profundidade de carbonatação.

Fonte: Autores (2016).

A Figura 3 apresenta os resultados obtidos no ensaio de verificação da profundidade de carbonatação.

Para relação a/agl 0,5 é notável a influência negativa da sílica ativa no aumento da profundidade de carbonatação apenas com a utilização de $15 \%$. Quando se aumentou a relação água/aglomerante para 0,7 as amostras de referência (sem adições) foram as que apresentaram menores profundidades de carbonatação, tendo em vista que possuem maiores teores de hidróxido de cálcio que os concretos com adições minerais. Nota-se que quanto maior o percentual da adição, maior a profundidade carbonatada. O resultado já era esperado de acordo com alguns pesquisadores como Helene [8], Monteiro [15] e Alves [17], tendo em vista que as reações pozolânicas consomem os álcalis livres resultantes da hidratação do clínquer, reduzindo a alcalinidade da pasta e consequentemente favorecendo a frente de carbonatação.

No entanto, as amostras com substituição de $10 \%$ de sílica ativa do presente estudo apresentaram uma redução de $13,08 \%$ da profundidade de carbonatação em comparação a amostra de referência para relação a/agl 0,5.

Sabe-se que concretos com elevada porosidade, na presença de umidade, estão mais sujeitos à 171 carbonatação. No entanto o gás carbônico gasoso na realidade não é reativo, porém na presença de água, forma o ácido carbônico, que reage com o hidróxido de cálcio gerando, entre os compostos principais, carbonato de cálcio.

Sabe-se também, que a utilização de sílica ativa em uma quantidade adequada dificulta a passagem dos agentes agressivos, pois aumenta a densidade da matriz de cimento, reduzindo o tamanho dos cristais e provocando refinamento da estrutura de poros tornando-o de baixa penetrabilidade, em função da interrupção na comunicação entre os poros pela sua ação. A redução do número e tamanho dos poros reflete na diminuição do transporte de massa para o interior do concreto, e consequentemente aumenta a durabilidade das estruturas, o que pode explicar a redução da profundidade carbonatada com substituição de $10 \%$ de sílica ativa nas amostras com relação a/agl 0,5.

Ainda pode-se perceber que as profundidades alcançadas foram na ordem de $96 \%$ a $112,62 \%$ maiores nas amostras com relação a/agl 0,7 , fato este, que mais uma vez reforça a importância da relação a/agl para determinar as características da pasta endurecida como a compacidade e porosidade, e consequentemente uma maior ou menor permeabilidade. Quanto maior a relação

http: //dx.doi.org/10.25286/repa.v2i3.714 
água/aglomerante, maior a profundidade de carbonatação.

Isaía afirmou que teores elevados de adições minerais tendem a diminuir o $\mathrm{pH}$, porém não o suficiente para despassivar a armadura [18], o que também foi evidenciado por Cadore [19]. Neville relata que ensaios feitos com pastas maduras de cimento Portland com alcalinidade elevada ( $\mathrm{pH}$ igual a $13,9)$ com adição de $10 \%$ de fumo de sílica apresentaram uma redução do $\mathrm{pH}$ de apenas 0,5 , e para $20 \%$ de adição a redução do $\mathrm{pH}$ foi de 1,0 , mostrando que mesmo assim o pH permaneceu acima de 12,5 , o que representa um valor adequadamente alto para proteção das armaduras contra a corrosão [20]. Nessas condições, vale verificar se os benefícios proporcionados pelas adições no que se refere à qualidade do concreto, dificultando a penetração de agentes agressivos como os cloretos, compensariam esta redução do $\mathrm{pH}$, uma vez que ela não é significante para despassivar a armadura.

Segundo Isaía, o efeito das adições minerais depende da forma com que a mistura é realizada, se por substituição ou por adição. O autor constatou para a mesma relação a/agl, que há uma diminuição da penetração de $\mathrm{CO}_{2}$ com a adição de cinza volante sem redução no teor de cimento, enquanto que, sob a forma de substituição de cimento há um acréscimo na profundidade de carbonatação [21].

\subsection{Ação de Cloretos}

A Figura 4 apresenta os resultados da profundidade de penetração de cloretos, onde observa-se que para relação água/aglomerante 0,5 , todas as amostras com as adições apresentaram um melhor desempenho quanto à proteção da pasta frente à penetração de cloretos.

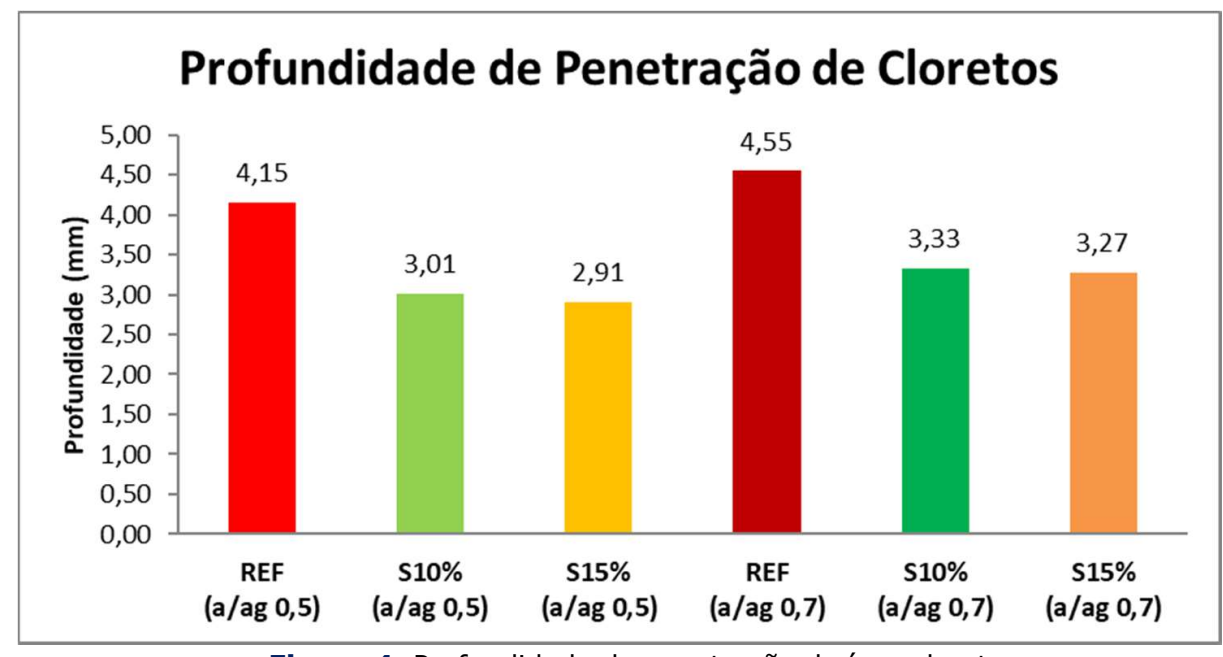

Figura 4: Profundidade de penetração de íons cloretos.

Fonte: Autores (2016).

As amostras com $15 \%$ de substituição apresentaram uma menor profundidade de penetração de cloretos em comparação as amostras com $10 \%$ de substituição, no entanto esta diferença foi bem pequena, estando de acordo com as pesquisas existentes que há uma "quantidade ótima" da adição para se obter seus benefícios, e a partir desta quantidade, os benefícios acrescidos seriam irrisórios.

A utilização de $10 \%$ e $15 \%$ de sílica ativa em substituição parcial do cimento resultou em uma redução de $27,47 \%$ e $29,88 \%$ na profundidade de penetração dos íons cloretos respectivamente para relação a/agl 0,5.
O mesmo comportamento se repete quando aumenta-se a relação a/agl para 0,7 , resultando em uma redução de $26,81 \%$ e $28,13 \%$ para $10 \%$ e $15 \%$ de substituição respectivamente.

Percebe-se ainda, que a utilização de adições com a finalidade de proteger a pasta contra a penetração de cloretos pode ser mais importante do que a própria relação água/aglomerante. As amostra com adições e relação a/agl 0,7 mostraram um melhor desempenho do que a amostra sem adições e relação a/agl 0,5. A profundidade de penetração das amostras de referência com relação a/agl 0,5 (sem adição) foi na ordem de 1,27 vezes maior do que a profundidade das 
amostras com utilização de $15 \%$ de sílica ativa com maior relação a/agl.

Outra observação importante é a pequena diferença de profundidade de penetração entre as amostras com relação a/agl 0,5 e 0,7. A sílica ativa possui elevada finura, e seu emprego aumenta a demanda de água das argamassas na ordem de $129 \%$ sendo necessária a utilização de aditivos fluidificantes ou plastificantes para que não afete a trabalhabilidade da argamassa. No entanto, com o objetivo de dar continuidade a pesquisa de Barros, não se utilizou aditivos nas amostras desta pesquisa, o que torna a pasta "mais seca", dificultando o adensamento quando não se aumenta a quantidade de água [22] Acredita-se que estas profundidades de penetração dos íons cloretos poderiam ser reduzidas mais ainda se houvesse o emprego adequado de aditivos.

\section{Discussões}

A sílica ativa propicia muitos benefícios às propriedades do concreto, tanto em relação a sua reologia no estado fresco, quanto ao comportamento mecânico e de durabilidade no estado endurecido. No entanto se torna evidente que as misturas com maiores teores de adição mineral, são fatores preponderantes para as reduções na alcalinidade do sistema, e consequentemente, maiores profundidades de carbonatação.

$\mathrm{Na}$ presente pesquisa perceberam-se os seguintes resultados:

Quanto à ação do $\mathrm{CO}_{2}$ :

- $\quad$ Substituições de $10 \%$ de sílica ativa para relação a/agl 0,5 se apresentou benéfico quanto a proteção contra a frente de carbonatação, reduzindo a profundidade carbonatada em 13,08\%,

- $\quad$ Substituições de $15 \%$ de sílica ativa para relação a/agl 0,5 não apresentaram um bom desempenho, portanto verificou-se que quanto maior o percentual da substituição, maior a profundidade de carbonatação.

- $\quad$ Os piores desempenhos para relação a/agl 0,5 não ultrapassaram $5,48 \%$ da profundidade carbonatada em comparação as amostras de referência.

- Para relação a/agl 0,7 não houve benefícios de proteção contra a frente de carbonatação, e também quanto maior o percentual de substituição, maior a profundidade alcançada devido a elevada porosidade.

- $\quad$ Os piores desempenhos para relação a/agl 0,7 chegaram a um aumento de 20,39\% da profundidade carbonatada para $15 \%$ de substituição por sílica ativa.

- A profundidade de carbonatação aumentou de $96 \%$ a $112.62 \%$ nas amostras com relação a/gl 0,7 em comparação as amostras com relação a/gl 0,5.

Quanto à ação de íons cloretos

- A sílica ativa se mostrou benéfica quanto à proteção da pasta frente à penetração de cloretos.

- Para relação a/agl 0,5 a utilização de $10 \%$ e $15 \%$ de sílica ativa em substituição parcial do cimento resultou em uma redução de $27,47 \%$ e $29,88 \%$ na profundidade de penetração dos íons cloretos respectivamente.

- Para relação a/agl 0,7 a utilização de $10 \%$ e $15 \%$ de sílica ativa em substituição parcial do cimento resultou em uma redução de $26,81 \%$ e $28,13 \%$ na profundidade de penetração dos íons cloretos respectivamente.

Destaca-se também a importância do uso de aditivos fluidificantes ou plastificantes em argamassas e concretos com utilização da sílica ativa que possuam baixa relação água/aglomerante para que se mantenham as mesmas condições de trabalhabilidade, e não se obtenha um efeito adverso pela dificuldade do adensamento e consequentemente maior porosidade na pasta.

\section{Conclusões}

Conclui-se, que a substituição parcial do cimento por sílica ativa, proporciona maior capacidade de proteção à penetração de íons cloreto e, consequentemente, maior durabilidade das estruturas de concreto. No entanto para compreender-se a capacidade de proteção frente à carbonatação é preciso novos estudos para encontrar a quantidade adequada que não cause efeitos contrários devido à redução da reserva alcalina. Contudo, para baixos valores de relação água/aglomerante, os benefícios que as adições podem trazer às características do concreto sobrepõem-se a possível redução da reserva alcalina, pois os acréscimos da profundidade carbonatada encontrados foram pequenos em comparação as amostras sem adições, e provavelmente não serão suficientes para a 
despassivação das armaduras, considerando concretos com alcalinidade inicial elevada e um cobrimento adequado. Este comportamento não se aplica para elevadas relações água/aglomerante.

Por este motivo, deve-se ter cautela nas escolhas dos materiais para cada finalidade aplicada, e atentarse ao uso de adições principalmente para utilização em ambientes com alta concentração de $\mathrm{CO}_{2}$.

Por fim, recomenda-se então o uso de sílica ativa com o objetivo de aumentar a proteção da pasta contra a ação de íons cloretos e consequentemente aumentar a vida útil das estruturas, contanto que sua aplicação não seja em ambientes com elevada concentração de $\mathrm{CO}_{2}$. Para estes casos, deve-se ter cautela na escolha do tipo e quantidade da adição mineral.

\section{Referências}

[1] MEHTA. P.K.; MONTEIRO, P.J.M. Concreto: Estrutura, propriedades e materiais. $2^{a}$ ed. São Paulo: Ed. Ibracon, 2014.

[2] PEDRoso, F.L. Concreto: as origens e a evolução do material construtivo mais usado pelo homem. Concreto e construções - IBRACON, edição 53, São Paulo, 2009.. Disponível em: <http://ibracon.org.br/publicacoes/revistas_ibrac on/rev_construcao/pdf/Revista_Concreto_53.pdf> . Acesso em: 30 mar. 2017.

[3] BARBOSA, F.R.; CARVALHO, J.R; COSTA e SILVA, A.J.; FRANCO, A.P.G; MOTA, J.M.F. Corrosão de armadura em estrutura de concreto armado devido ao ataque de íons cloreto. $54^{\circ}$ Congresso Brasileiro de Concreto. Maceió, 2012.

[4] GEMELLI, E. Corrosão de Materiais Metálicos e sua Caracterização. Rio de Janeiro: LTC, 2001.

[5] FIGUEIREDO, E.J.P.; MEIRA, G.R. Corrosão das armaduras de concreto. Boletín Técnico ALCONPAT Internacional. México, 2013.

[6] HELENE, P.R.L. RIBEIRO, D. V. (Org.). Corrosão em estruturas de concreto armado: Teoria, controle e métodos de análise. $1^{a}$ Edição, Rio de Janeiro: Elsevier, 2014.
[7] BARATA, M.S. Concreto de alto desempenho no estado do Pará: Estudo de viabilidade técnica e econômica de produção de concreto de alto desempenho com os materiais disponíveis em Belém através do emprego de adições de sílica ativa e metacaulim. Porto Alegre, 188 p., 2001. Dissertação (Mestrado em Engenharia) Universidade Federal do Rio Grande do Sul.

[8] HELENE, P.R.L. Contribuição ao estudo da corrosão em armaduras de concreto armado. São Paulo, 1993. Tese de Livre Docência - Escola Politécnica da Universidade de São Paulo.

[9] NEVILLE, A.M. Propriedades do Concreto. 912 f. 5a Edição. Porto Alegre: Ed. Bookman, 2015.

[10] Monteiro, E.C.B.; Pereira, V.C.O. Study of the Protective Capacity of Cements Regarding Corrosion of Reinforcements under Joint Action of $\mathrm{CO}_{2}$ and Chloride Ions. Journal of Civil Engineering and Architecture, v. 9, p 1017-1024, 2015.

[11] KIHARA, Y.; VISEDO, G.A indústria do cimento e o desenvolvimento do Brasil. Associação Brasileira de Cimento Portland, 2014. Disponivel em:

<http://www.abcp.org.br/conteudo/imprensa/aindustria-do-cimento-e-o-desenvolvimento-dobrasil>. Acesso em: 02 Abr 2017.

[12] UNI 7928. Determination of chloride ion penetration. Italian Standard 7928. Roma. 1978.

[13] RILEM RECOMMENDATIONS. CPC-18 Measurement of hardened concrete carbonation depth. 1988. p. 453-455.

[14] ASSOCIAÇÃO BRASILEIRA DE NORMAS TÉCNICAS. NBR 7215 - Cimento Portland Determinação da resistência à compressão. Versão corrigida 1997. Rio de Janeiro, 1996.

[15] MONTEIRO, E.C.B. Estudo da capacidade de proteção de alguns tipos de cimentos nacionais, em relação à corrosão de armaduras sob a ação conjunta de $\mathrm{CO}_{2}$ e íons cloretos. Brasília, 165 p., 1996. Dissertação (Mestrado em estruturas) Faculdade de Tecnologia da Universidade de Brasília. 
[16] NT BUILD 492. Concrete, mortar and cementbased repair materials: chloride migration coeficiente from non-steady-state migratoin experimets. Nordtest. Finlândia, 1990-11

[17] ALVES, A.S. Efeitos Físicos e Químicos de Misturas Pozolânicas na Carbonatação e Penetrabilidadde à Água no Concreto de Alto Desempenho. 2000. Dissertação (Mestrado) Universidade Federal de Santa Maria. 2000.

[18] ISAIA, G.C. Efeitos de misturas binárias e ternárias de pozolanas em concreto de elevado desempenho: um estudo de durabilidade com vistas à corrosão da armadura. São Paulo, 1995. Tese (Doutorado) - Escola Politécnica, Universidade de São Paulo.

[19] CADORE, W.W. Estudo da carbonatação da camada de cobrimento de protótipos de concreto com altos teores de adições minerais e cal hidratada. Santa Maria, 150 p., 2008. Dissertação (Mestrado em Engenharia) - Universidade Federal de Santa Maria.

[20] NEVILLE, A.M. Propriedades do Concreto. $2^{a}$ Edição. Porto Alegre: Ed. Pini, 1997. 828 p.

[21] ISAIA, G.C. Carbonatação de concreto: uma revisão. Santa Maria, 1999. Departamento de Estruturas e Construção Civil, Universidade Federal de Santa Maria.

[22] BARROS, T.C.M.F. Análise da resistência mecânica de concretos produzidos com adição de metacaulim e sílica ativa em comparação ao concreto convencional. Recife, 69 p., 2015. Trabalho de conclusão de curso - Universidade Católica de Pernambuco. 